Current Opinion in Microbiology

Review for Environmental Microbiology Section

\title{
Prokaryotic functional gene diversity in the sunlit ocean: stumbling in the dark
}

1

2

3

Departament de Biologia Marina i Oceanografia, Institut de Ciències del Mar, CSIC, Barcelona, Catalunya, Spain

${ }^{\dagger}$ Equal contributors to this article

"Corresponding author:

Dpt. Biologia Marina i Oceanografia Institut de Ciències del Mar, CSIC

Pg Marítim de la Barceloneta 37-49

E-08003 Barcelona, Catalunya, Spain

Phone: +34 932309500

Fax: + 34932309555

email: iferrera@icm.csic.es 


\section{Abstract}

29 Prokaryotes are extremely abundant in the ocean where they drive

30 biogeochemical cycles. The recent development and application of -omics

31 techniques has provided an astonishing amount of information revealing the

32 existence of a vast diversity of functional genes and a large heterogeneity within

33 each gene. The big challenge for microbial ecologists is now to understand the

34 ecological relevance of this variability for ecosystem functioning, a question that

35 remains largely understudied. This brief review highlights some of the latest

36 advances in the study of the diversity of biogeochemically relevant functional

37 genes in the sunlit ocean.

\section{Introduction}

39 The ocean is the largest ecosystem on Earth. Prokaryotes are the most abundant

40 cells in the ocean (ca. $\left.\sim 10^{29},[1]\right)$ where they are the engines driving nutrient

41 cycles and energy flow. In the last two decades, molecular studies based on

42 rRNA genes have unveiled that the phylogenetic diversity of marine

43 microorganisms is immensely larger than the few thousand species formally

44 described [2]. After the initial surveys of ribosomal genes, the study of protein-

45 coding genes followed by the development of meta'omics approaches has

46 opened a window to the exploration of marine microbial diversity at the functional

47 level. In fact, the first large-scale ocean metagenomic survey identified novel

48 protein families and added a tremendous diversity to known protein families [3]. 
49 Hence, the study of functional diversity has improved our view of the roles that

50 marine microbes play in global biogeochemical cycles.

51 Some clear examples are the discovery of novel metabolisms, such as

52 proteorhodopsin-driven photoheterotrophy [4], or the role that urea plays in

53 nitrification by marine archaea [5]. These studies have shown that prokaryotes

54 play more functions than previously thought and that there is large sequence

55 diversity for each gene [6-9]. But, what are the ecological implications of this

56 variability? Addressing this important question is a major challenge in marine

57 microbial ecology.

58 The tremendous functional diversity of marine prokaryotes occurs at different

59 levels of complexity, such as variability in gene content, differences in operon

60 structure, heterogeneity in gene sequence, or existence of different proteins

61 which drive redundant functions. Furthermore, the presence of functional

62 metabolic genes in viral genomes, such as those reported to be involved in

63 photosynthesis, carbon or phosphorus metabolism, have added another

64 dimension to this complexity [10]. Most of the studies conducted so far have

65 focused on genes that confer an ecological advantage to prokaryotic populations,

66 such as nitrogen fixation or photoheterotrophy. In this review, we summarize the

67 current knowledge in prokaryotic (mostly bacterial) functional gene diversity in

68 relation to the four major marine biogeochemical cycles (carbon, phosphorus,

69 sulfur and nitrogen) (Figure 1). We focus on the sunlit ocean where most of the

70 studies have been conducted, and discuss the potential relevance of genetic

71 diversity for ecosystem functioning. 


\section{Biogeochemically relevant genes in the sunlit ocean}

73 Carbon cycle. The paradigm of the ocean carbon flow depicting phototrophs as

74 the only autochtonous producers of organic carbon (C) and heterotrophic

75 bacteria as the consumers fell apart in the last decade. Nowadays we know that

76 mixotrophy, the ability of an organism to use both light and organic matter to

77 obtain energy, seems to be the rule rather than the exception in sunlit marine

78 microbial communities. Since the discovery of a proteorhodopsin (PR) gene in a

79 metagenomic fragment almost 15 years ago [4], we now know that up to $80 \%$ of

80 bacteria inhabiting surface waters can harbor this gene [11]. Proteorhodopsins

81 display large genetic diversity [12] that translates for example in different spectral

82 tuning, likely as an adaptation to absorb the prevalent light wavelengths (blue or

83 green) found in different marine waters. While this proton pump has been

84 demonstrated to enhance growth under light in certain marine Bacteroidetes [13],

85 no direct effect on growth was observed in Pelagibacter, in which, however, PR

86 increased long-time survival during starvation [14], as was also observed in a

87 Vibrio isolate [15]. Recently, new types of evolutionarily distinct rhodopsins have

88 been uncovered which translocate either $\mathrm{Na}^{+}$or $\mathrm{Cl}^{-}[16,17]$. Interestingly,

89 multiple rhodopsin types, each with different ion specificities, can be found within

90 a single strain of marine Bacteroidetes [17]. However, the ecological implications

91 of containing as many as three functionally different rhodopsins are unknown.

92 Rhodopsin is indeed a neat example in which gene diversity likely results in

93 diverse physiological and ecological functions. Yet, we appear to know only a

94 small fraction of the functional significance of the diversity of this gene. 
95 Similarly, aerobic anoxygenic phototrophs (AAPs) can derive a portion of their

96 energy requirements harvesting light using bacteriochlorophyll a ( $\mathrm{BChl} a)$. Marine

97 AAPs contain diverse pufM gene sequences (the phylogenetic marker for AAPs)

98 as well as puf operon structures that delimit several phylogroups distributed

99 across the Alpha- and Gammaproteobacteria. Recent experimental work with

100 isolates has shown that while light is the main factor controlling the regulation of

$101 \mathrm{Bchl}$ a in representatives of the Alphaproteobacteria, this is not the case in the

102 Gammaproteobacteria [18]. Likewise, evidences that distinct phylogroups have

103 preferences to live under different environmental conditions $[8,19,20]$ suggest

104 that different AAPs posses diverse strategies to adapt to a changing environment

105 and may have different roles in the functioning of the ecosystem. However, a

106 direct linkage between puf diversity and its relevance in ecosystem function has

107 not yet been established.

108 CO lithoheterotrophy has also received attention as a potential form of obtaining 109 energy for bacterial metabolism [21]. $\mathrm{CO}$ is formed through the photochemical

110 degradation of organic matter in sunlit waters and can be oxidized by means of

111 the carbon monoxide dehydrogenase encoded by the cox genes [22]. These

112 genes are structured in operons that form two phylogenetically distinct groups, in

113 which the gene order also diverges. Some bacterial species contain one operon

114 from each phylogenetic group, whereas others can contain multiple operons of

115 the same group. The active site configuration of the two phylogenetic groups also

116 differs. Although the significance of these distinctions has not yet been resolved,

117 it is believed that they may affect substrate specificity and activity [22]. 
118 Nevertheless, although CO oxidation mediated by bacterioplankton is

119 biogeochemically significant, the energy obtained through this process seems to

120 have a negligible effect on bacterial metabolism [23].

121 Besides their ability to obtain energy from light, some heterotrophic bacteria may

122 obtain additional carbon by fixing $\mathrm{CO}_{2}$ through RuBisCO [24], or anaplerotic

123 pathways [25]. Nevertheless, mixotrophy is not restricted to heterotrophic

124 prokaryotes. It was recently shown that Prochlorococcus cells use a sugar

125 transporter gene to take up glucose to tune their carbon metabolism [26] and

126 other evidences of organic matter incorporation by cyanobacteria exist [e.g., 27].

127 Yet, a major challenge to our comprehension of the global carbon cycle is to

128 understand bacterial processing of dissolved organic carbon (DOC). DOC is

129 composed by thousands of compounds, many of them uncharacterized, and

130 utilized by a diverse community of heterotrophic bacteria with varying enzymatic

131 capabilities and ecological strategies for carbon metabolism [28]. The number of

132 studies dealing with specific genes encoding for these enzymatic activities is

133 notably limited, with the exception of the genes involved in chitin degradation

134 [29]. Currently, meta'omics allows depicting the diverse enzymes involved in

135 DOC utilization [30]. However, the functional annotation of the genes encoding

136 these enzymes is frequently based on distant homology to proteins characterized

137 in non-marine isolates, which may translate into a misinterpretation of their

138 function. Besides the utilization of complex DOC compounds, genes encoding

139 pathways for demethylation and C1 oxidation have been identified in SAR11 and

140 other marine bacteria like Roseobacter or methylotrophs, supporting the 
141 hypothesis that $\mathrm{C} 1$ oxidation might be a mechanism by which dissolved organic

142 carbon is significantly recycled to $\mathrm{CO}_{2}$ in the upper ocean [31].

143 Phosphorus cycle. Phosphorus (P) availability is one of the dominant selective

144 forces driving niche partitioning and ecotype divergence in oceanic prokaryote 145 populations [32]. Inorganic phosphate $\left(P_{i}\right)$ is the preferred source of $P$ for 146 prokaryotes, and they have evolved mechanisms for monitoring and responding

147 to fluctuations of this essential nutrient. The Pho regulon integrates the sensing 148 of $\mathrm{P}_{\mathrm{i}}$ availability with co-regulation of genes involved in $\mathrm{P}_{\mathrm{i}}$ scavenging (like pstS)

149 or the use of alternative sources of $\mathrm{P}$, such as phosphoesters (through phoA, 150 phoX, phoD and other phosphatase genes), phosphonates (phn genes) and 151 phosphite (ptx genes) [33,34]. Recent studies show that bacteria inhabiting 152 permanent P-depleted areas of the ocean contain a higher number and diversity 153 of Pho regulon genes, thereby increasing their ability to obtain $P$ [32]. A recent 154 study provides a remarkable example among the ubiquitous SAR11, which 155 despite their streamlined genomes display striking differences in their P-related 156 gene content. An isolate from the P-rich northeast Pacific Ocean is only able to 157 grow on phosphate, whereas a strain isolated from the P-deprived Sargasso Sea 158 can utilize a broad range of alternative compounds for $\mathrm{P}$ nutrition [35]. Similar 159 results have been observed in Prochlorococcus strains pointing out how the 160 environment shapes the genetic diversity of different bacterial populations $161[32,36]$.

162 Sulfur cycle. The marine sulfur cycle has been focus of intense research in the 163 last years due to the potential role of dimethylsulphide (DMS) in regulating 
164 climate. Dimethylsulphoniopropionate (DMSP) is released by some 165 phytoplankton cells and is either demethylated to methylmercaptopropionate 166 (MMPA), or cleaved to DMS by DMSP lyases [37,38]. DMS is a volatile 167 compound that is later photo-oxidized to sulfate aerosols that form cloud 168 condensation nuclei, initiating cloud cover over the oceans which leads to 169 increases in albedo. As for the other essential nutrients, the combination of 170 classical techniques and -omics has been crucial for the advancement on the

171 knowledge of sulfur cycling in the ocean. Metagenomic data revealed that the key 172 gene in the demethylation process $(d m d A)$ is diverse among different taxa and 173 can be up to two orders of magnitude more abundant that DMSP lyases [38].

174 Indeed, the demethylation pathway provides reduced carbon for energy or 175 biomass and reduced sulfur that can be incorporated into S-containing 176 aminoacids or oxidized for energy. Hence, this pathway seems ecologically more 177 advantageous in oligotrophic environments than the cleavage pathway.

178 Nevertheless the DMSP lyases are a wide group of enzymes that seem to 179 catalyze the same reaction, whereas $d m d A$ is the only known demethylase [37].

180 Nitrogen cycle. Traditionally, Trichodesmium and other heterocyst-forming 181 cyanobacteria were thought to be the predominant $\mathrm{N}_{2}$-fixing microorganisms in 182 the ocean [39]. However we currently know that unicellular cyanobacteria such 183 as Croscosphaera watsonii [40] or the prymnesiophyte symbiont UCYN-A [41], 184 together with heterotrophic bacteria [6] dominate the diazotrophic community in 185 ocean surface waters. Furthermore, ammonia-oxidizing archaea were discovered 186 a decade ago [12] and are now known to be responsible for most of the 
187 nitrification in the upper ocean [42]. These findings have arisen interest towards

188 genes involved in $\mathrm{N}$ cycling with several studies that have explored the diversity

189 of nifH (involved in nitrogen fixation) and amoA (involved in ammonia oxidation)

190 among other genes. Some of these studies have allowed linking gene diversity

191 with functional significance. For example, a recent study showed that two distinct

192 types of archaeal amoA genes have different biogeographies, one operating at

193 medium, and one at low ammonia concentrations [43]. In addition, recent

194 metagenomic analyses have shown that Thaumarchaeota contain genes

195 involved in urea transport and degradation (ure $A$, ure $B$, ure $C$ genes) and that

196 these organisms may fuel nitrification in oceanic polar regions [5].

\section{Towards understanding functional diversity}

198 Rapid technological development has enabled the description of the functional

199 diversity of ocean microbes. Yet, the astonishing amount of genetic information

200 generated is not accompanied by a significant improvement in our understanding

201 of its functional significance and therefore, many relevant ecological questions

202 remain unsolved. Here, we discuss some of these questions.

203 What is the significance of the genetic variability for well-studied genes?

204 Molecular techniques have unveiled the diversity of the key players in marine

205 biogeochemical cycles and how genetic diversity is structured in relation to 206 environmental variables. For example, differential effects of abiotic factors on

207 AAP bacteria harboring different pufM sequences suggest that not all

208 phylogroups are functionally and ecologically equal [8]. Likewise, experimental 
209 data have shown that the abundance of different sequence clusters of the

210 demethylation gene $d m d A$ linked to specific marine taxa including Roseobacter-

211 and SAR11-like bacteria, correlate with certain environmental characteristics [38].

212 A global study of nifH-harboring bacterioplankton has reveled specific

213 biogeography for different taxa [6]. Additionally, studies on diversity of enzymes

214 degrading organic compounds show that there is a whole suit of different

215 enzymes carrying out the same function but with very different kinetics [44],

216 probably reflecting the heterogeneity of substrate concentration at the microscale

217 [45]. Microbes may also overcome limitation of enzyme cofactors by swapping

218 out one metal for another in the same enzyme [46] or synthesizing different

219 metalloenzymes for the same purpose. For example, calcium based

220 phosphatases like PhoX and PhoD seem to be prevalent in oligotrophic waters,

221 as opposed to the classical zinc-binding form of the enzyme (PhoA) $[33,47]$.

222 Nevertheless, perhaps the best-known example of the significance of genetic

223 variability is the case of the rhodopsins, which as seen above, display large

224 genetic diversity that translates into various physiological and ecological 225 functions.

226 What is the function of the astounding number of hypothetical proteins? -Omics

227 datasets contain thousands of sequences encoding hypothetical proteins whose

228 characterization requires tedious experimental work. While the genetic

229 engineering approach is rarely conducted in marine studies, the results obtained

230 so far stress its value. Heterologous expression was used to prove that

231 proteorhodopsins are light-induced proton pumps [4] and through mutagenesis 
232 we learned more about their differential spectral tuning [48]. Functional screening

233 of fosmid libraries allowed the identification of a phosphonatase pathway as well

234 as a novel pair of genes that allow utilization of 2-aminoethylphosphonate,

235 alternative sources of $\mathrm{P}$ for marine microorganisms [49]. These approaches have

236 led to major advances in our understanding of functional diversity and thus, more

237 effort should be put in applying these techniques to advance in our knowledge of

238 the functional capabilities within microbial populations.

239 What genes are actually expressed and what environmental variables regulate

240 gene expression? Metatranscriptomic studies provide insights into which genes

241 are transcribed, and therefore likely expressed, in the environment. Comparative

242 expression studies have evidenced for example that coexisting heterotrophic

243 bacterial populations exhibit diel oscillations in their expression patterns,

244 resembling those shown by their photosynthetic counterparts [50], or that

245 bacterioplankton increase the transcription of genes involved in cell aggregation

246 when accompanying a phytoplankton bloom [51]. Studies combining both

247 metagenomics and metatranscriptomics are essential to better understand what

248 genes are expressed under which circumstances, but these studies are only

249 starting to appear [52]. Furthermore, current metatranscriptomic studies recover

250 only a very small percentage of the total pool of transcripts $(-0.000001 \%$, [52]).

251 Significant gains in the analysis of biogeochemically informative gene expression

252 patterns require a greater sequencing investment. Initiatives like the global

253 circumnavigation expedition TARA Oceans [53] are presently applying massively

254 high-throughput sequencing to describe the functional profiles of the world's 
255 oceans and promise to greatly advance our understanding of ecosystem

256 functioning. Yet, to understand what factors drive the observed trends, a precise

257 characterization of the environment is necessary, something that is not always

258 conducted.

259 What mechanisms drive the observed functional genetic diversity? Comparative

260 gene and genome analyses have revealed the ecological and evolutionary forces

261 that influence genome content. Genome streamlining seems to be a successful

262 adaptation to live under permanent low nutrient concentration, as seen in SAR11,

263 Prochlorococcus [54] and in wide array of marine single amplified genomes [55].

264 However, even those reduced genomes display a significant variability in gene

265 content among closely related populations. As mentioned above, one of the

266 dominant selective forces driving niche partitioning and ecotype divergence

267 within these populations is nutrient availability [32]. Indeed, many of the genes

268 involved in the efficient acquisition of nutrients are horizontally transferred and

269 often found in genomic islands [32]. For example, certain microdiverse lineages

270 of uncultured Prochlorococcus harbor a genomic island that contains the genes

271 necessary to assimilate nitrite and nitrate, as opposed to their cultured

272 representatives that rely on ammonia [56]. Likewise, alkaline phosphatases

273 (phoA, phoX and $p h \circ D$ ) are not found in SAR11 isolates, but are present in

274 uncultured representatives of this ubiquitous clade $[47,57]$. Phosphatases are

275 needed for the utilization of a major component of the dissolved organic P pool,

276 and have broad substrate specificity. Therefore, the acquisition of just one

277 phosphatase gene enables the cell to access a wide spectrum of $\mathrm{P}$ compounds, 
278 which can be very advantageous in oligotrophic environments. Other examples of

279 horizontally transferred genes are those involved in the adaptation to different

280 light regimes or in obtaining additional energy from light [59]. Moreover, genomic

281 islands are enriched in genes encoding hypothetical proteins which could play a

282 role in increasing bacterial fitness under changing environmental conditions [60],

283 but determining their function is necessary to confirm this hypothesis. Thus,

284 despite not being the only mechanism (e.g. mutation), horizontal gene transfer is

285 largely responsible for the observed diversity.

286 In summary, although several key questions remain to a large extend

287 unanswered, the -omics approach provide a framework for evaluating functional

288 gene diversity in an environmental context while at the same time is a powerful

289 tool to formulate hypotheses on microbially mediated processes. What the field is

290 currently lacking is taking a step further to experimentally test -omics emerged

291 hypotheses. Function-driven metagenomics and combination of -omics with

292 classical microbiology techniques are necessary to obtain a more comprehensive

293 view of the functioning of the very complex marine microbial communities, a

294 relevant matter for marine ecology.

\section{Acknowledgments}

296 The author's work is partially supported by grants DEVOTES (FP7-ENV-2012-

297 308392) and MICRO-3B (FP7-OCEAN-2011-287589) funded by European

298 Union, grants HOTMIX (CTM2011-30010/MAR), DOREMI (CTM2012-34294) and 
PANGENOMICS (CGL2011-26848) funded by the Spanish Government, and

300 grant XTM (2014SGR/1179) funded by the Catalan Government.

301

302

303

304

305

306

307

308

309

310

311

312

313

314

315

316

\section{REFERENCES}

1. Whitman WB, Coleman DC, Wiebe WJ: Prokaryotes: the unseen majority. Proc Natl Acad Sci USA 1998, 95:6578-6583.

2. Pedrós-Alió C: Marine microbial diversity: can it be determined? Trends in microbiology. Trends Microbiol 2006, 14:257-263.

3. Yooseph S, Sutton G, Rusch DB, Halpern AL, Williamson SJ, Remington $\mathrm{K}$, Eisen JA, Heidelberg KB, Manning G, Li W, Jaroszewski L et al.: The Sorcerer II Global Ocean Sampling expedition: expanding the universe of protein families. PLoS Biol 2007, 5:e16

4. Béjà $O$, Aravind L, Koonin EV, Suzuki MT, Hadd A, Nguyen LP, Jovanovich SB, Gates C, Feldman RA, Spudich JL et al:: Bacterial rhodopsin: evidence for a new type of phototrophy in the sea. Science 2000, 289:19021906.

5. Alonso-Sáez L, Waller AS, Mende DR, Bakker K, Farnelid H, Yager PL, Lovejoy $C$ et al.: Role for urea in nitrification by polar marine Archaea. Proc Natl Acad Sci USA 2012,109:17989-17994.

6. Farnelid $\mathrm{H}$, Andersson AF, Bertilsson $\mathrm{S}$, Al-Soud WA, Hansen LH, Sørensen S, Steward GF, Hagström A, Riemann L: Nitrogenase gene amplicons from global marine surface waters are dominated by genes of non-cyanobacteria. PLoS One 2011, 6:e19223.

7. Fernàndez-Guerra $A$, Casamayor EO: Habitat-associated phylogenetic community patterns of microbial ammonia oxidizers. PLOS One 2012, 7:e47330.

8. Ferrera I, Borrego CM, Salazar G, Gasol JM: Marked seasonality of aerobic anoxygenic phototrophic bacteria in the coastal NW Mediterranean Sea as revealed by cell abundance, pigment concentration and pyrosequencing of pufM gene. Environ Microbiol 2014, 16:2953-2965. ( $\left.{ }^{*}\right)$

This study applied for the first time high throughput sequencing to investigate the diversity of the functional gene pufM and showed that it is larger than previously reported. The results show a clear seasonality of different phylogroups suggesting that AAP subpopulations replace each other over time. Furthermore, differential effects of abiotic factors on different groups were determined likely indicating that not all AAP phylogroups are functionally and ecologically equal. 
9. Varaljay VA, Gifford SM, Wilson ST, Sharma S, Karl DM, Moran MA:

338 Bacterial dimethylsulfoniopropionate degradation genes in the oligotrophic 339 North Pacific Subtropical Gyre. Appl Environ Microbiol 2014, 78: 2775-2782.

$340 \quad\left(^{*}\right)$

341 An exhaustive study of the diversity of the dimethylsulfoniopropionate (DMSP) demethylase gene, $d m d A$. The authors designed PCR primers targeting 10 environmental clades and subclades of the DmdA protein, and showed that $d m d A$ richness in free-living versus particle-associated bacteria differs. The paper also highlights how the availability of metagenomic sequence data has significantly enhanced the design of PCR primer pairs for targeting key functional genes.

10. Breitbart. Marine viruses: Truth or dare. Ann Rev Mar Sci 2012, 4:425448.

11. DeLong $E F$, Béjà $O$ : The light-driven proton pump proteorhodopsin enhances bacterial survival during tough times. PLOS Biol 2010, 8:e1000359.

12. Venter JC, Remington K, Heidelberg JF, Halpern AL, Rusch D, Eisen JA, Wu D, Paulsen I, Nelson KE, Nelson W et al.: Environmental genome shotgun sequencing of the Sargasso Sea. Science 2004, 304:66-74.

13. Gómez-Consarnau L, González JM, Coll-Lladó M, Gourdon P, Pascher T, Neutze R, Pedrós-Alió C, Pinhassi J: Light stimulates growth of proteorhodopsin-containing marine Flavobacteria. Nature 2007, 445:210213.

14. Steindler L, Schwalbach MS, Smith DP, Chan F, Giovannoni SJ: Energy starved Candidatus Pelagibacter ubique substitutes light-mediated ATP production for endogenous carbon respiration. PLoS One 2011, 6:e19725.

15. Gómez-Consarnau L, Akram N, Lindell K, Pedersen A, Neutze R, Milton DL, González JM, Pinhassi J: Proteorhodopsin phototrophy promotes survival of marine bacteria during starvation. PLOS Biol 2010, 8:e1000358.

16. Kwon SK, Kim BK, Song JY, Kwak MJ, Lee CH, Yoon JH, Oh TK, Kim JF: Genomic makeup of the marine flavobacterium Nonlabens (Donghaeana) dokdonensis and identification of a novel class of rhodopsins. Genome Biol Evol 2013, 5:187-199. $\left(^{* *}\right)$

This study uncovered a gene encoding an unexpected type of microbial rhodopsin containing a characteristic NQ motif, which forms a phylogenetically distinct group. Genomic and metagenomic surveys demonstrated the prevalence of this rhodopsin among microbial communities inhabiting hypersaline environments, suggesting its involvement in sodium metabolism and the sodium-adapted lifestyle. This paper is a good example of how gene diversity may result in diverse physiological and ecological functions. 
17. Yoshizawa S, Kumagai $\mathrm{Y}$, Kim H, Ogura $\mathrm{Y}$, Hayashi T, Iwasaki W, et al.: Functional characterization of flavobacteria rhodopsins reveals a unique class of light-driven chloride pump in bacteria. Proc Natl Acad Sci USA 2014, 111:6732-6737. $\left({ }^{* *}\right)$

A recent report on a new light-driven chloride pump found in a marine bacterium, the flavobacterium Nonlabens marinus. Interestingly, this bacterium also possesses a proteorhododpsin and a light-driven sodium pump, being the first reported microbe to possess three functionally different types of rhodopsins.

18. Spring S, Riedel T: Mixotrophic growth of bacteriochlorophyll acontaining members of the OM60/NOR5 clade of marine gammaproteobacteria is carbon-starvation independent and correlates with the type of carbon source and oxygen availability. BMC Microbiol 2013, 13:117.

19. Yutin N, Suzuki MT, Teeling H, Weber M, Venter JC, Rusch DB, Béjà O: Assessing diversity and biogeography of aerobic anoxygenic phototrophic bacteria in surface waters of the Atlantic and Pacific Oceans using the Global Ocean Sampling expedition metagenomes. Environ Microbiol 2007, 9:1464-1475.

20. Waidner LA, Kirchman DL: Diversity and distribution of ecotypes of the aerobic anoxygenic phototrophy gene pufM in the Delaware estuary. Appl Environ Microbiol 2008, 74:4012-4021.

21. Moran MA, Miller WL: Resourceful heterotrophs make the most of light in the coastal ocean. Nat Rev Microbiol 2007, 5:792-800.

22. King GM, Weber CF: Distribution, diversity and ecology of aerobic cooxidizing bacteria. Nat Rev Microbiol 2007, 5: 107-118.

23. Cunliffe M: Physiological and metabolic effects of carbon monoxide oxidation in the model marine bacterioplankton ruegeria pomeroyi DSS-3. Appl Environ Microbiol 2013, 79:738-740.

24. Newton RJ, Griffin LE, Bowles KM, Meile C, Gifford S, Givens CE, et al.: Genome characteristics of a generalist marine bacterial lineage. ISME $J$ 2010, 4:784-798.

25. Palovaara J, Akram N, Baltar F, Bunse C, Forsberg J, Pedrós-Alió C, González JM, Pinhassi J: Stimulation of growth by proteorhodopsin phototrophy involves regulation of central metabolic pathways in marine planktonic bacteria. Proc Natl Acad Sci USA 2014, 111:3650-3658. ( $\left.{ }^{*}\right)$

This study explores the metabolic pathways mediating the light responses of proteorhodopsin-containing bacteria. Changes in gene expression between light and dark conditions revealed a tightly regulated shift in central metabolic 
pathways. Carbon acquisition pathways seem to shift towards anaplerotic $\mathrm{CO}_{2}$ fixation in the light. Their results show that regulatory interactions between dissolved organic carbon quality and central metabolic pathways critically determine the fitness of surface ocean bacteria engaging in proteorhodopsin phototrophy.

26. Muñoz-Marín MC, Luque I, Zubkov MV, Hill PG, Diez J, García-Fernández JM: Prochlorococcus can use the Pro1404 transporter to take up glucose at nanomolar concentrations in the Atlantic Ocean. Proc Natl Acad Sci USA 2013, 110:8597-8602. $\left(^{* *}\right)$

It was known that autotrophic cyanobacteria could incorporate organic compounds containing limiting nutrients, and this paper experimentally shows that Prochlorococcus can take up glucose to tune their metabolism to energetically benefit from changing environmental conditions. To prove this hypothesis, these authors introduced the gene that confers the capability for glucose uptake in a cyanobacterium unable to take up glucose. Furthermore, they were able to observe glucose uptake by Prochlorococcus in the environment.

27. Gómez-Pereira PR, Hartmann M, Grob C, Tarran GA, Martin AP, Fuchs BM, Scanlan DJ, Zubkov MV: Comparable light stimulation of organic nutrient uptake by SAR11 and Prochlorococcus in the North Atlantic subtropical gyre. ISME J 2013, 7:603-614.

28. Kujawinski EB: The impact of microbial metabolism on marine dissolved organic matter. Ann Rev Mar Sci 2011, 3:567-599.

29. Beier S, Bertilsson S: Bacterial chitin degradation-mechanisms and ecophysiological strategies. Front Microbiol 2013, 4:149. ( $\left.{ }^{*}\right)$

A comprehensive review on the different mechanisms and the principal steps involved in chitin degradation at the molecular level while discussing the coupling of bacterial community composition to the measured chitin hydrolysis activities and substrate uptake rates.

30. Teeling H, Fuchs BM, Becher D, Klockow C, Gardebrecht A, Bennke CM, Kassabgy $M$, Huang $S$, Mann AJ, Waldmann J: Substrate-controlled succession of marine bacterioplankton populations induced by a phytoplankton bloom. Science 2012, 336:608-611.

31. Sun J, Steindler L, Thrash JC, Halsey KH, Smith DP, Carter AE, Landry ZC, Giovannoni SJ: One carbon metabolism in SAR11 pelagic marine bacteria. PLoS One 2011, 6:e23973.

32. Coleman ML, Chisholm SW: Ecosystem-specific selection pressures revealed through comparative population genomics. Proc Natl Acad Sci USA 2010, 107, 18634-18639. 
33. Sebastian M, Ammerman JW: The alkaline phosphatase PhoX is more widely distributed in marine bacteria than the classical PhoA. ISME J 2009, 3:563-572.

458 34. Martínez A, Osburne MS, Sharma AK, DeLong EF, Chisholm SW: 459 Phosphite utilization by the marine picocyanobacterium Prochlorococcus 460 MIT9301. Environ Microbiol 2012, 14:1363-1367.

461 35. Carini P, White AE, Campbell EO, Giovannoni SJ: Methane production by phosphate-starved SAR11 chemoheterotrophic marine bacteria. Nat Commun 2014, 5:4346 $\left(^{* *}\right)$

This study shows that despite having streamlined genomes, SAR11 strains display striking differences in their phosphorus (P)-related gene content depending on the phosphate concentration of the waters where they were isolated from. Due to differences in gene content, the isolate from P-rich Northeast Pacific only grows on phosphate, whereas the isolate from the Pdeprived Sargasso Sea is able to grow on different sources of $P$. Interestingly, the Northeast Pacific isolate initiates a general stress response upon Pdepletion because is not able to adapt to fluctuations of this essential nutrient.

36. Martiny AC, Coleman ML, Chisholm SW: Phosphate acquisition genes in Prochlorococcus ecotypes: Evidence for genome-wide adaptation. Proc Natl Acad Sci USA 2006, 103:12552-12557.

37. Curson AR, Todd JD, Sullivan MJ, Johnston AW: Catabolism of dimethylsulphoniopropionate: microorganisms, enzymes and genes. Nat Rev Microbiol 2011, 9:849-859.

38. Moran MA, Reisch CR, Kiene RP, Whitman WB: Genomic insights into bacterial DMSP transformations. Ann Rev Mar Sci 2012, 4:523-442.

39. Bergman B, Sandh G, Lin S, Larsson J, Carpenter EJ: Trichodesmium-a widespread marine cyanobacterium with unusual nitrogen fixation properties. FEMS Microbiol Rev 2013, 37:286-302.

40. Moisander PH, Beinart RA, Hewson I, White AE, Johnson KS, Carlson CA, Montoya JP, Zehr JP: Unicellular cyanobacterial distributions broaden the oceanic $\mathbf{N}_{2}$ fixation domain. Science 2010, 327:1512-1514.

41. Zehr JP, Kudela RM: Nitrogen cycle of the open ocean: from genes to ecosystems. Ann Rev Mar Sci 2011, 3:197-225.

42. Newell SE, Facwett SE, Ward BB. Depth distribution of ammonia oxidation rates and ammonia-oxidizer community composition in the Sargasso Sea. Limnol Oceanogr 2013, 58:1491-1500. 
43. Sintes E, Bergauer K, De Corte D, Yokokawa T, Herndl GJ: Archaeal amoA gene diversity points to distinct biogeography of ammonia- oxidizing Crenarchaeota in the ocean. Environ Microbiol 2013, 15:1647-1658 $\left(^{*}\right)$

494 An example on how genetic diversity may translate into functional significance. 495 Using two different amoA primer sets, these authors show that distinct ecotypes differential affinities for ammonia, one operating at medium and the other at low concentrations.

44. Arrieta JM, Herndl GJ: Changes in bacterial $\beta$-glucosidase diversity during a coastal phytoplankton bloom. Limnol Oceanogr 2002, 47:594-599.

45. Dittmar $\mathrm{T}$, Stubbins A: Dissolved organic matter in aquatic systems. In: Birrer B, Falkowski P, Freeman K (eds) Treatise of Geochemistry. 2nd edition, Elsevier, 2014, 12: 125-156.

46. Dupont CL, Neupane K, Shearer J, Palenik B: Diversity, function and evolution of genes coding for putative Ni-containing superoxide dismutases. Environ Microbiol 2008, 10: 1831-1843.

47. Kathuria S, Martiny AC: Prevalence of a calcium-based alkaline phosphatase associated with the marine cyanobacterium Prochlorococcus and other ocean bacteria. Environ Microbiol 2011, 13:74-78.

48. Man D, Wang W, Sabehi G, Aravind L, Post AF, Massana R, Spudich EN, Spudich JL, Béja O: Diversification and spectral tuning in marine proteorhodopsins. EMBO J 2003, 22:1725-1731.

49. Martinez A, Tyson GW, Delong EF: Widespread known and novel phosphonate utilization pathways in marine bacteria revealed by functional screening and metagenomic analyses. Environ Microbiol 2010, 12: 222-223.

50. Ottesen EA, Young CR, Gifford SM, Eppley JM, Marin R, Schuster SC, Scholin CA, DeLong EF: Multispecies diel transcriptional oscillations in open ocean heterotrophic bacterial assemblages. Science 2014, 345:207-212. $\left.{ }^{* *}\right)$

Ottesen et al. apply metatranscriptomics to samples collected during three days to analyze the in situ expression profiles of naturally occurring oceanic bacterial populations. They find that unexpectedly, several different heterotrophic bacterioplankton groups display diel cycling in many of their gene transcripts. These waves of diel gene transcription may influence both the tempo and the mode of matter and energy transformation in the sea.

51. Rinta-Kanto JM, Sun S, Sharma S, Kiene RP, Moran MA: Bacterial community transcription patterns during a marine phytoplankton bloom. Environ Microbiol 2012, 14:228-239. 
52. Satinsky BM, Crump BC, Smith CB, Sharma S, Zielinski BL, Doherty M, Meng J, Sun S, Medeiros PM, Paul JH et al.: Microspatial gene expression

530 patterns in the Amazon River Plume. Proc Natl Acad Sci USA 2014, 531 111:11085-11090. $\left({ }^{* *}\right)$

532 This article performs the first fully quantitative inventory of genes and transcripts and expression of genes mediating elemental cycling at the microspatial scale in the ocean's largest river plume, the Amazon River Plume. These authors hypothesize that in response to patchiness in carbon, nutrients, and light at the micrometer scale, Amazon Plume microbes regulate the expression of genes relevant to biogeochemical processes at the ecosystem scale.

53. Karsenti E, Acinas SG, Bork P, Bowler C, De Vargas, C, Raes J, Sullivan $\mathrm{M}$, Arendt D, Benzoni F, Claverie JM et al.: A holistic approach to marine ecosystems biology. PLoS Biology 2011, 9:e1001177

54. Giovannoni SJ, Thrash JC, Temperton B: Implications of streamlining theory for microbial ecology. ISME J 2014, 8:1553-1565.

A review addressing the implications of genome streamlining in both symbiotic and commensal bacteria, as well as in cosmopolitan free-living bacteria having small genomes. The causes of genome reduction in these two groups of organisms are different but they imply loss of function. The consequences of reductive evolution in streamlined organisms are discussed.

55. Swan BK, Tupper B, Sczyrba A, Lauro FM, Martinez-Garcia M, González JM, Luo H, Wright JJ, Landryh ZC, Hansoni NW et al:: Prevalent genome streamlining and latitudinal divergence of planktonic bacteria in the surface ocean. Proc Natl Acad Sci USA 2013, 110:11463-11468. $\left(^{* *}\right)$

Using large-scale single cell genomics, this paper explores the genome content of many bacterial lineages inhabiting the surface ocean. By comparison with existing cultures, they found that natural bacterioplankton have smaller genomes, fewer gene duplications, and are depleted in guanine and cytosine, noncoding nucleotides, and genes encoding transcription, signal transduction, and non-cytoplasmic proteins. These findings provide strong evidence that genome streamlining and oligotrophy are prevalent features among diverse free-living bacterioplankton.

56. Martiny AC, Kathuria S, Berube PM: Widespread metabolic potential for nitrite and nitrate assimilation among Prochlorococcus ecotypes. Proc Natl Acad Sci USA 2009, 106:10787-10792.

57. Luo $\mathrm{H}$, Moran MA: Assembly-free metagenomic analysis reveals new metabolic capabilities in surface ocean bacterioplankton. Environ Microbiol Rep 2013, 5:686-696 
567 58. Coleman ML, Sullivan MB, Martiny AC, Steglich C, Barry K, DeLong EF, 568 Chisholm SW: Genomic islands and the ecology and evolution of 569 Prochlorococcus. Science 2006, 311:1768-1770.

570 59. Cho JC, Stapels MD, Morris RM, Vergin KL, Schwalbach MS, Givan SA, 571 Barofsky DF, Giovannoni SJ: Polyphyletic photosynthetic reaction centre 572 genes in oligotrophic marine Gammaproteobacteria. Environ Microbiol 2007, 573 9:1456-1463.

574 60. Fernández-Gómez B, Fernàndez-Guerra A, Casamayor EO, González JM, 575 Pedrós-Alió C, Acinas SG: Patterns and architecture of genomic islands in 576 marine bacteria. BMC Genomics 2012, 13:347. 


\section{$578 \quad$ Figure legends}

579 Figure 1. Simplified view of major biogeochemical cycles in the sunlit ocean. 580 Solid lines indicate prokaryotic mediated processes and the key functional genes 581 involved in the processes are shown in boxes. Asterisks denote groups of genes 582 with a related function. Briefly, phytoplankton fix carbon through photosynthesis, 583 incorporate inorganic nutrients and release dissolved organic matter, which 584 includes dissolved organic carbon (DOC), dissolved organic phosphorus (DOP), 585 and dissolved organic nitrogen (DON). Certain phytoplankton species also release dimethylsulphoniopropionate (DMSP). Zooplankton also excretes dissolved organic matter, including urea. Prokaryotes, especially heterotrophic bacteria but also certain cyanobacteria, use the organic matter released by phyto- and zooplankton, and compete with phytoplankton for the inorganic nutrients. DMSP can be either cleaved by different DMSP lyases (encoded by $d d d$ genes) to DMS and eventually released to the atmosphere, or demethylated by $d m d A$ and used by prokaryotes as a reduced sulfur source. DOC is metabolized by a diverse number of enzymes, such as glucosidases, sulfatases or chitinases, but only the chitinases genes are well characterised. DOP is mainly composed of phosphoesters and phosphonates, which to be used require the action of alkaline phosphatases (phoX, phoA, phoD) and phosphonates genes (phn genes). The key enzymes for the utilization of DON are aminopeptidases, but the molecular basis of these enzymes is still largely unknown. Some heterotrophic bacteria are able to obtain additional carbon by fixing $\mathrm{CO}_{2}$ through RuBisCO $(r b c L)$ or alternative pathways (see main text for details). Other heterotrophic bacterial cells can obtain additional energy from sunlight by means of the proteorhodopsin or the puf operon, or from the oxidation of carbon monoxide (CO). Prokaryotes can obtain nitrogen from ammonia $\left(\mathrm{NH}_{4}{ }^{+}\right)$or nitrate $\left(\mathrm{NO}_{3}{ }^{-}\right)$, and some cyanobacteria and heterotrophic bacteria are capable of fixing $\mathrm{N}_{2}$ by means of nitrogenases ( $\left.n i f\right)$. The oxidation of ammonia in the sunlit ocean is mainly performed by archaea by means of the amoA gene, and the degradation of urea (ure genes) plays a major role in fuelling this process. Viruses lyse prokaryotic and eukaryotic cells, releasing DOM, particulate organic matter and nutrients. Viruses also play a crucial role in the exchange of genetic information among marine prokaryotes. 


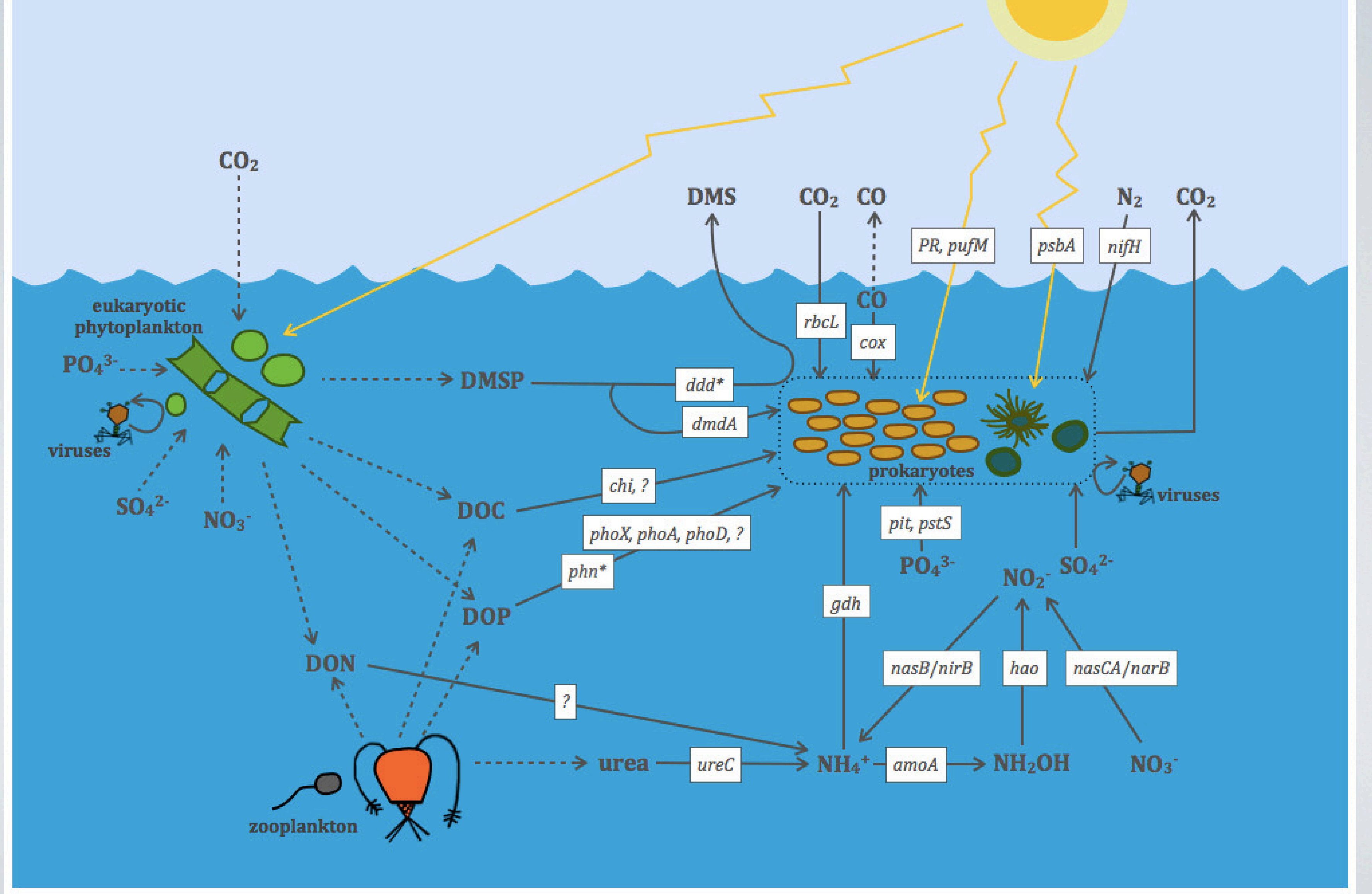

